Thrombocytopenia associated with lithium carbonate

Dr S Collings (Bethlem and Maudsley Joint Hospitals, London) writes: a 24 year old woman who had taken lithium carbonate for nine years was admitted in a hypomanic state. Lithium, which she had stopped some weeks earlier, was reintroduced at $750 \mathrm{mg}$ daily. Thioridazine was given for three days. The platelet count on admission was $140 \times 10^{9} / 1$ and the white count $13.0 \times 10^{9} / 1\left(4-11 \times 10^{9} / 1\right)$. Seventeen days after admission the platelet count fell (see graph) with a leucocytosis of $18 \cdot 38 \times 10^{\circ} / 1$. The platelets were immature forms. There were no purpura or signs of lithium toxicity.

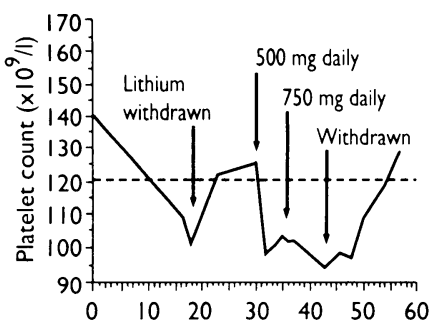

Effect of lithium on platelet count (dashed line represents lower limit of normal)

The serum lithium concentration was $0.5 \mathrm{mmol} / \mathrm{l}$. Platelet counts over the previous nine years had been normal. Lithium was withdrawn and the platelet count recovered to $125 \times 10^{\circ} / 1$. When lithium was reinstated at $500 \mathrm{mg}$ daily the platele count fell to $100 \times 10^{\%} / 1$. Chlorpromazine was introduced as the woman's mental state deteriorated. With advice that lithium could be continued while the platelet coun remained over $95 \times 10^{9} / 1$, the dose was increased to regain a therapeutic concentration. After nine days, and at a lithium concentration of $0.6 \mathrm{mmol} / \mathrm{l}$, the platelet count had fallen further. Lithium was stopped, allowing recovery. The leucocyte count was now $8 \times 10^{\%} / 1$, the leucocytosis having been attributed to a productive cough which subsided without treatment. Subsequently the patient was maintained on low dose flupenthixol. Over the next four months, the platelet count remained at $130-140 \times 10^{9} / 1$.

I have been unable to find other reports of thrombocytopenia caused by lithium. Lithium can cause neutrophilic leucocytosis, a property used in treating iatrogenic neutropenia.' Aplastic and megaloblastic anaemias have been reported, ${ }^{2}$ and the Committee on Safety of Medicines has one report of death from haemolytic anaemia. The effects of lithium on platelets include a raised platelet count and amelioration of cytotoxic induced thrombocytopenia. $^{+5}$ Lithium enhances production of colony stimulating factor in vivo and in vitros and may protect haemopoetic stem cells against cytotoxic drugs. ${ }^{\circ}$ The mechanism for this hitherto undescribed action of lithium carbonate is unclear.

1 Lyman GH, William CC, Preston D. The use of lithium carbonate to reduce infection and leukopenia during systemic chemotherapy. $N$ Engl f Med 1980;302:257-60.

2 Hussain MZ, Khan AG, Chaudhry ZA. Aplastic anemia associated with lithium therapy. Can Med Assoc f 1973;108:724-8.

Prakash R, Sethi N, Agrawal SS, Kushwah MR, Sethi BB. A case report of megaloblastic anemia secondary to lithium. Am $\mathcal{F}$ Psychiatry 1981;138:849.

4 Joffe RT, Kellner CH, Post RM, Ulde TW Lithium increases platelet count. $N$ Engl $f$ Med 1984;311:674-5.

5 Richman CM, Makii MM, Weiser PA, Herbst AL. The effect of lithium carbonate on chemotherapy induced neutropenia and thrombocytopenia. Am f Hematol 1984;16: 313-23.

6 Gallichio VS. Diminished 4-hydroperoxycyclophosphamide induced cytotoxicity of hematopoietic bone marrow stem cell progenitors with lithium chloride. Med Sci Res 1987;15:691-2.

\section{Visual loss and optic atrophy associated with cyproterone acetate}

Drs $H$ Markus and $M$ Polkey and Professor M HARRISON (Department of Neurology, Middlesex Hospital, London W1N 8AA) write: We report a case of visual failure and optic atrophy associated with cyproterone acetate.

An 80 year old man with previously normal vision presented in January 1991 with a five month history of bilateral deteriorating vision. Ten weeks earlier he had been seen in an ophthalmic casualty department, where corrected visual acuity of $6 / 12$ bilaterally had been recorded; pupillary reflexes were normal but bilateral optic atrophy was noted. $\mathrm{He}$ had been treated with digoxin $0.25 \mathrm{mg} /$ day for atrial fibrillation for 30 years. In June 1988 he underwent a transurethral resection of his prostate for urinary hesitancy; prostatic chippings showed a moderately differentiated adenocarcinoma. At this time there was no evidence of metastatic spread. In July 1988 he started cyproterone acetate $100 \mathrm{mg}$ three times a day. The dose was reduced to $50 \mathrm{mg}$ three times a day in March 1989 owing to malaise and nausea. Bone scans and acid phosphatase concentrations had remained normal. He was a non-smoker and drank only occasional beers. He had a normal diet.

On admission 10 days after presentation corrected acuity in the left eye had deteriorated to light-dark perception only. There was a left afferent pupillary defect. Ishihara plates were: right $6 / 14$ correct and left unable to read control plate. Intraocular pressure was $15 \mathrm{~mm} \mathrm{Hg}$ bilaterally. The right visual field was normal. Both eyes showed pale optic discs with sharp margins and normal retinal appearances with no pigmentary retinopathy. Systemic examination was normal apart from controlled atrial fibrillation. The results of the following investigations were normal: biochemical screen; thyroid function; erythrocyte sedimentation rate; $\mathrm{C}$ reactive protein; serum vitamin B12 and folate; acid phosphatase; prostatic specific antigen; cerebrospinal fluid pressure, protein, microscopy and cytospin; syphilis serology; autoantibody screen; brain and orbital computed tomography; intravenous cerebral angiography; and temporal artery biopsy. Visua evoked potentials were unrecordable from the left eye and delayed at $128 \mathrm{~ms}$ on the right.

The cyproterone acetate was stopped and replaced by goserelin. Multivitamins were also started. By February subjective visual acuity had improved and he could see shapes with the left eye. By April 1991 corrected acuity had improved to: right $6 / 12$, left $6 / 24$. Ishihara colour plates were: right $9 / 14$ correct, left $1 / 14$. Visual evoked potentials were now obtainable from the left eye with a latency of $142 \mathrm{~ms}$.

The temporal relation between discontinuing the cyproterone acetate and the improvement in visual acuity suggests a possible causal association between the drug and impaired vision and optic atrophy. The normal values for prostatic specific antigen and acid phosphatase, normal bone scan, and the absence of any clinical evidence of prostatic carcinoma together with the subsequent improvement in visual acuity make a non-metastatic complication an unlikely cause of the visual failure. There have been no reports of an association between cyproterone acetate and bilateral optic atrophy either published or in manufacturers' records.

\section{Mesalazine induced lupus-like syndrome}

Dr M T Dent, Mr S Ganapathy, D C D HoldsworTh, and Dr K C CHANNER (Royal Hallamshire Hospital, Sheffield) write: We describe a patient taking mesalazine who developed severe pleuropericarditis associated with immunological features typical of drug induced lupus syndrome.

A 38 year old white woman presented in February 1991 with severe distal proctitis. She was treated with prednisolone suppositories $5 \mathrm{mg}$ at night and sulphasalazine $1.5 \mathrm{~g} /$ day Within a few days she developed a systemic illness with fever, malaise, and flu-like symptoms. The sulphasalazine was discontinued, with prompt resolution of her symptoms. After a week she was started on mesalazine $1.2 \mathrm{~g} /$ day with no il effects. Seven months later she presented with a five week history of pleuritic central chest pain radiating to the left shoulder, increasing dyspnoea, night sweats, and extreme lassitude. On examination she looked

unwell with a fever of $38 \cdot 5^{\circ} \mathrm{C}$, tachycardia, and signs of a left pleural effusion.

Electrocardiography showed a reduced $Q R S$ voltage and widespread $T$ wave inversion. Chest radiography showed an enlarged cardiac silhouette and confirmed a left pleural effusion. Echocardiography showed good left ventricular function (ejection fraction $81 \%$ ) and a moderate sized pericardial effusion without evidence of tamponade. Viral serology gave negative results while immunoserological investigations were strongly positive for antinuclear antibody $(1 / 300)$ and negative for rheumatoid factor and double strand DNA nuclear histone, smooth muscle, and mitochondrial antibodies. Both $\operatorname{Ig} M$ and IgG immune complexes were present. C3 concentration was normal while $\mathrm{C} 4$ was marginally depressed at $0 \cdot 19 \mathrm{~g} / \mathrm{l}$ (normal $0 \cdot 20$ $0 \cdot 65$ ). Drug induced lupus syndrome was diagnosed and mesalazine discontinued. Within 24 hours the patient's temperature had settled while the effusions and lassitude resolved over eight weeks. Immun profile returned to normal, though antinuclear factor was still presen $(1 / 100)$ two months later.

Pericarditis associated with sulphasalazine induced lupus syndrome is well recognised. ${ }^{\prime 2}$ The sulphapyridine moiety has been suggested as the most likely causative agent ${ }^{\prime}$ and no similar reaction has yet been reported with mesalazine, which lacks the sulphapyridine group. Pericarditis has been reported after mesalazine, but the onset within two weeks of treatment and negative immunoserological findings were not typical of lupus-like syndrome. ${ }^{3}$ Our patient developed symptoms some months after starting treatment and presented with large effusions and immunoserological findings compatible with drug induced lupus syndrome. Immunoserological findings were not available from her previous reaction to sulphasalazine, which might have been a similar reaction, although its early onset was more characteristic of the commoner nonlupus type of hypersensitivity reaction. We suggest that the sulphapyridine moiety is not necessary for the development of lupus syndrome with this class of drugs and that such a reaction should be considered in patients who become unwell after several months of treatment

We thank Dr A Milford-Ward for advice and in whose laboratories the 